\title{
In situ hybridization and promoter analysis reveal that cotton leaf curl Multan betasatellite localizes in the phloem
}

\author{
O. EINI ${ }^{1}$, M. S. RASHEED ${ }^{2 *}$ J. W. RANDLES ${ }^{2}$
}

${ }^{1}$ Plant Protection Department, College of Agriculture, University of Zanjan, Zanjan, Iran; ${ }^{2}$ School of Agriculture, Food and Wine, The University of Adelaide, Waite Campus, SA 5064, Australia

Received November 7, 2016; accepted January 13, 2017

\begin{abstract}
Summary. - Begomoviruses (the family Geminiviridae) have either a monopartite or a bipartite (DNA A and DNA B) single-stranded DNA genome. DNA B contains the open reading frame for movement protein and enables some bipartite begomoviruses to invade non-phloem tissues, whereas monopartite begomoviruses are limited to the phloem. Betasatellite DNA replicates in association with some monopartite begomoviruses to produce severe symptoms and enhance replication of helper virus in some hosts. The cotton leaf curl Multan betasatellite (CLCuMuB) has been shown to substitute for the DNA B of a bipartite begomovirus by permitting systemic infection, but the tissue tropism and the role of betasatellites in releasing monopartite begomoviruses from the phloem to adjacent tissue has not been described. In this study, the tissue tropism of CLCuMuB and a monopartite helper virus, tomato leaf curl virus (ToLCV), has been investigated using in situ hybridization, promoter localization and analysis of transgenic $2 \beta$ plants, which contain a dimer of the CLCuMuB genome. In situ hybridization showed that CLCuMuB and ToLCV were localized into the vascular tissue of infected plants. In addition, $\mathrm{CLCuMuB}$ was detected only in the vascular tissue of $2 \beta$ transgenic plants after infection with ToLCV. $\beta$-glucuronidase (GUS) expression under the $\beta C 1$ promoter was also limited to the phloem tissues. In conclusion, we showed for the first time that CLCuMuB localizes only in the phloem tissues and unlike the DNA B component, CLCuMuB is unable to release the monopartite helper virus out of phloem tissues.
\end{abstract}

Keywords: betasatellite; geminivirus; phloem; tissue tropism

\section{Introduction}

Begomoviruses (the genus Begomovirus, the family Geminiviridae) have either monopartite or bipartite (DNA A and DNA B) genomes (Stanley et al., 2005). The tissue tropism of begomoviruses is genetically determined (Morra and Petty, 2000) and different patterns of tissue tropism have been reported for bipartite begomoviruses. For example, Abutilon mosaic

E-mail: Omid.eini@znu.ac.ir; phone: +98-2433052266.

*Present address: Patheon Biologics, 37 Kent Street, Woolloongabba, QLD4102, Australia.

Abbreviations: $\mathrm{CLCuMuB}=$ cotton leaf curl Multan betasatellite; $\mathrm{CLCuMuV}=$ cotton leaf curl Multan virus; $\mathrm{GUS}=\beta$-glucuronidase; ISH = in situ hybridization; TGMV = tomato golden mosaic virus; ToLCV = tomato leaf curl virus virus (AbMV) was detected and retained in the phloem tissues of infected plants, whereas two other bipartite begomoviruses, African cassava mosaic virus (ACMV) and tomato golden mosaic virus (TGMV), were detected in nearly all tissue types. The ability of ACMV and TGMV to move out of Nicotiana benthamiana phloem tissues was found to be correlated with the development of severe symptoms in comparison with mild symptoms produced by infection with the phloem-limited AbMV (Wege et al., 2001). DNA B contains the open reading frame for movement protein and enables some bipartite begomoviruses to invade non-phloem tissues; whereas a number of monopartite begomoviruses are phloem-limited (Rojas et al., 2001; Selth et al., 2005) and similarly to most monopartite begomoviruses, DNA A of bipartite begomoviruses can invade only phloem tissue (Rojas et al., 2005).

One of the factors that may support tissue tropism of a plant virus could be the promoter activity of viral genes (Yin 
et al., 1997a). The activity of most viral promoters studied in transgenic plants was limited to the phloem cells; this may reflect the ability of most viruses, including geminiviruses, to multiply within these cells and, therefore, the systemic infection of the host plant and their dissemination by phloemfeeding insect vectors. For example, phloem-specific gene expression has been reported for geminiviruses such as wheat dwarf virus (Dinant et al., 2004) and maize streak virus (Mazithulela et al., 2000), both from the genus Mastrevirus, using the GUS (uidA) reporter gene in a stable system.

Tissue localization of plant viruses can be investigated using in situ hybridization (ISH), which is a robust technique for the detection of specific nucleic acid sequences and analysis of gene expression during development processes (McFadden, 1989). The principle of ISH is the same as for other nucleic acid hybridization methods. The major difference is that ISH involves the hybridization of nucleic acids located within fixed cells. This technique has been used successfully for detection of monopartite (Bian et al., 2006) and bipartite begomoviruses (Weigel et al., 2015).

Betasatellites are circular, single-stranded satellite DNA associated with certain monopartite begomoviruses. Betasatellites contain a single gene, $\beta C 1$, which encodes a pathogenicity protein important for symptom expression (Cui et al., 2004; Saunders et al., 2004; Saeed et al., 2005) and suppression of gene silencing (Gopal et al., 2007; Eini et al., 2012; Saeed et al., 2015). Expression of this gene in $2 \beta$ transgenic tobacco plants containing a dimer of cotton leaf curl Multan betasatellite (CLCuMuB) resulted in an abnormal phenotype (Saeed et al., 2005). A more severe symptom was observed in plants infected with a complex of betasatellite and both cognate, cotton leaf curl Multan virus (CLCuMuV), and non-cognate, tomato leaf curl virus (ToLCV), helper viruses compared to the helper virus alone (Briddon et al., 2001; Saeed et al., 2005; Eini et al., 2009a). In some host plants, betasatellite enhances the replication of helper virus (Briddon et al., 2001), which can be explained by suppression of the host silencing system or supporting the release of the helper virus to non-phloem tissues.

Betasatellites functionally resemble DNA B from bipartite begomoviruses. For example, substitution of DNA B with CLCuMuB was shown to enable the systemic movement of DNA A from bipartite begomoviruses (Saeed et al., 2007). The DNA B of the non-phloem-limited bean dwarf mosaic virus (BDMV) was shown to move the phloemlimited AbMV, a bipartite begomovirus, out of the phloem (Levy and Czosnek, 2003). However, a similar role for the betasatellites was not shown. In this study, we investigated tissue localization of CLCuMuB and a monopartite helper virus, tissue targeting of $\beta C 1$ promoter and the possible role of betasatellite in moving the helper viruses out of phloem tissues using in situ hybridization and promoter localization in infected and transgenic plants. We show for the first time that CLCuMuB is localized in the vascular tissue of infected plants and that the $\beta C 1$ promoter is also phloem-specific. Unlike DNA B, CLCuMuB did not facilitate release of the monopartite helper virus from the phloem tissues.

\section{Materials and Methods}

Plant materials and virus clones. $N$. benthamiana plants were used in this study for tissue tropism of CLCuMuB and the helper virus. Transgenic tobacco lines, called $2 \beta$, carrying a head-to-tail dimeric construct of CLCuMuB have been described before (Saeed et al., 2005). Agroinfectious constructs of CLCuMuB and ToLCV have been described previously (Dry et al., 1993; Briddon et al., 2000; Saeed et al., 2005).

Virus inoculation and infectivity assays. To investigate tissue localization of CLCuMuB and helper viruses in infected plants, $N$. benthamiana plants at the 4-5 leaf stage were co-inoculated with an overnight culture of Agrobacterium tumefaciens (strain C58) containing the infectious viral clone of ToLCV together with infectious clone of CLCuMuB as described by (Kheyr-Pour et al., 1991).

To test virus and betasatellite infection, developing leaves from individual plants (50-100 mg) were collected for dot-blot analysis as described (Stonor et al., 2003). Then, young infected leaves were collected 3-4 weeks post-inoculation and processed for in situ hybridization as described below.

In another experiment, $2 \beta$ transgenic tobacco plants were agroinoculated with infectious clone of ToLCV. Leaf tissues were collected from inoculated plants after four weeks of inoculation. These tissues were used for section preparation and in situ hybridization.

In situ hybridization. Leaf samples were collected from plants infected with ToLCV or CLCuMuB together with ToLCV and also from $2 \beta$ transgenic tobacco plants infected with ToLCV. For in situ hybridization, the collected leaf tissues were fixed and sections, 6 to $8 \mu \mathrm{m}$ thick, were placed on silane-coated slides (ProSciTech, Thuringowa Central, Australia). Prehybridization, hybridization, and posthybridization were performed as described (Guerin et al., 2000). Probes were detected using Fast Red (Roche Diagnostics) or Western Blue (Promega Corp.) substrates. The slides were dehydrated, mounted in Entellan mounting medium, and observed under a light microscope (Carl Zeiss, Jena, Germany).

To prepare nonradioactive probes for in situ hybridization, ToLCV primers corresponding to the C4 (Table 1, P1 and P2) ORF were used to amplify viral DNA fragments by PCR. The $\beta C 1$ ORF from CLCuMuB was also amplified by PCR using P3/P4 primers (Table 1). The amplified DNAs were ligated into a pGEM-T Easy vector (Promega Crop, U.S.A.). The clones were used as templates for transcription using T7 or SP6 DNA-dependent RNA polymerase (Promega Corp.) in the presence of $\alpha^{32} \mathrm{P}$-UTP according to the manufacturer's instruction. RNA probes used for in situ hybridization were labeled with fluorescein-12-dUTP (for the probe from the complementary-sense gene) and digoxigenin-11-dUTP (for the probe from the virion-sense gene) using fluorescein or DIG 
Table 1. Oligonucleotide primers used in this study

\begin{tabular}{|c|c|c|c|}
\hline Primers & Description & Size (nt) & Sequences $\left(5^{\prime}\right.$ to 3 ) \\
\hline P1 & ToLCV C4-F & 26 & $\begin{array}{l}\text { GGGAATTCAGCAAGCGA } \\
\text { CCAGCAGAT }\end{array}$ \\
\hline $\mathrm{P} 2$ & ToLCV C4-R & 23 & $\begin{array}{l}\text { GGCCATCCT TA A T T C } \\
\text { TGAATCGA }\end{array}$ \\
\hline P3 & CLCuMB C1-F & 27 & $\begin{array}{l}\text { CCGCATATGTCATACATC } \\
\text { TGAATTCAT }\end{array}$ \\
\hline $\mathrm{P} 4$ & CLCuMB C1-R & 27 & $\begin{array}{l}\text { CCGATGACAATCAAAT } \\
\text { ACAACAACATG }\end{array}$ \\
\hline
\end{tabular}

Underlined sequences correspond to specific restriction enzyme sites.

RNA Labeling Mix, respectively (Roche Diagnostics, Castle Hill, Australia). The viral genome organization, position and orientation of the probes are shown in Fig. 1.

Plant transformation. A Binary construct harbouring the fulllength $\beta C 1$ promoter fused to $\beta$-glucuronidase (GUS), called $\beta 989$, was prepared (Eini et al., 2009a). This construct was introduced into A. tumefaciens LBA4404 by electroporation with a Gene Pulser apparatus (BioRad). Agrobacterium-mediated transformation of tobacco leaf discs (N. tabacum cv. Samsun) was carried out essentially as described (Horsch et al., 1985). Regenerated kanamycin resistant plants were grown in the glasshouse and the presence of the CLCuMuB promoter was confirmed by PCR. GUS activity and expression was tested in $\mathrm{T} 1$ plants.

RNA isolation and analysis. RNA was extracted from five lines of transgenic $\beta 989$ and PBI121 tobacco leaves using RNA extraction reagent (Invitrogen, Carlsbad, CA, USA). Total RNA (10 $\mu \mathrm{g})$ was electrophoresed and blotted onto nylon membrane (BioRad,
Hercules, CA, USA). The blotted membrane was hybridized with ${ }^{32} \mathrm{P}$-dCTP- labelled full length GUS gene as described (Sambrook and Russell, 2001).

Histochemical localization and quantification of GUS activity. Leaf tissues from five individual lines that express GUS driven by the full length $\beta C 1$ promoter were used for GUS staining as described (Jefferson et al., 1987). Thin sections of the GUS-stained transgenic $\beta 989$ tissues were prepared. Briefly, plant tissues were fixed, washed and then dehydrated through a graded acetone series to $100 \%$ and embedded in Spurr's resin (Spurr, 1969). Blocks were trimmed and photographed using bright field microscopy.

Quantitative GUS fluorometric assays with a Hitachi F-4010 fluorometer were conducted according to Jefferson et al. (1987) for leaf tissues of $\beta 989$ and pBI121-GUS transgenic plants. This experiment was repeated two times, using five tobacco plants for each treatment.

\section{Results}

\section{Plant infectivity}

$N$. benthamiana plants were infected with CLCuMuB and ToLCV at a high rate. Accumulation of CLCuMuB and the helper virus in infected plants was confirmed by dot blot assay (Fig. 2). These plants were used for further analysis.

\section{CLCuMuB localizes with the helper virus in phloem tissues}

Tissue tropism for CLCuMuB and ToLCV was studied by in situ hybridization. Both CLCuMuB and the helper virus, (a)

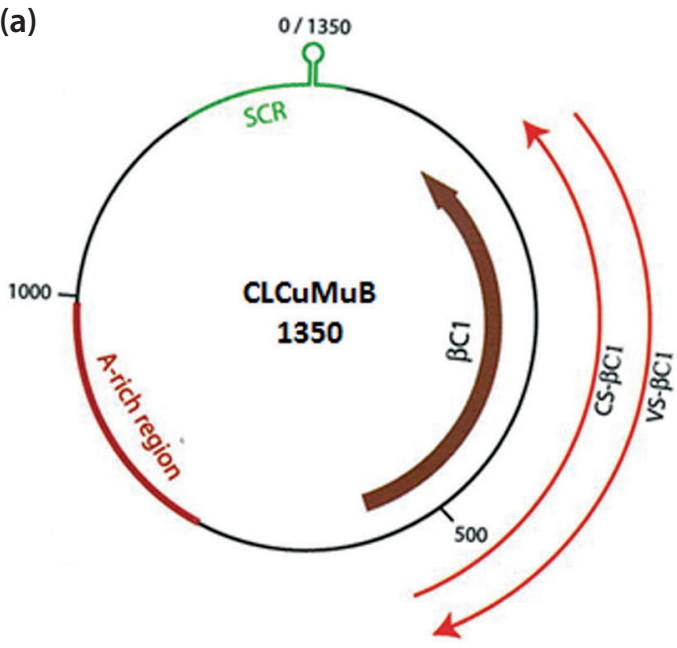

(b)

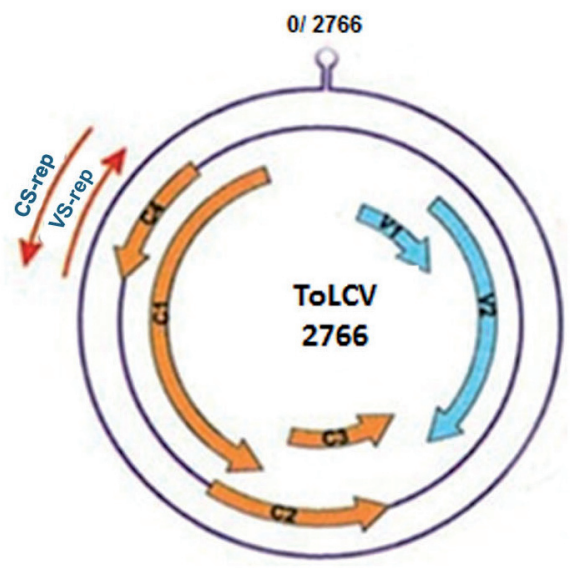

Fig. 1

Genome organization of CLCuMuB (a) and ToLCV (b) molecules that show the position and orientation of strand-specific RNA probes (thin arrows)

ORFs on the virion-sense (clockwise) strand and the complementary-sense (anticlockwise) strand are shown by arrows. The relative position of the satellite conserved region (SCR) and A-rich region are colored. VS = virion sense, CS = complementary sense. 


\section{ToLCV probe}
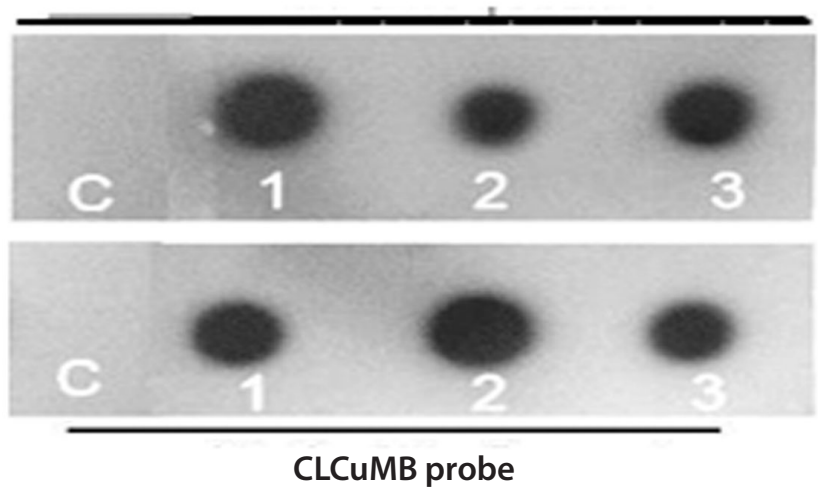

Fig. 2

Dot blot hybridization for detection of CLCuMuB and helper virus, ToLCV, in the inoculated tobacco plants

The upper panel shows ToLCV accumulation in inoculated plants for three (1-3) individual plants. The lower panel shows CLCuMuB accumulation in three (1-3) individual plants. Healthy $N$. benthamiana plants were used as control (C).

ToLCV, were detected in the vascular tissues of systemically infected plants and signals were not detected in other cell types outside the vascular tissues (Fig. 3). Hybridization signals were not found in the sections of uninfected tissues of $N$. benthamiana plants (Fig. 3A).

To identify CLCuMuB and ToLCV signals in the same cell, fluorescein-labelled ToLCV-specific probe and DIGlabelled CLCuMuB-specific probes were used. Dual in situ hybridization exhibited a distinct purple chromogenic output due to the masking of red ToLCV signals by the blue CLCuMuB signal (Fig. 3D), and confirmed that CLCuMuB was detectable in almost every cell where ToLCV had accumulated.
Detection of CLCuMuB in the vascular tissue of $2 \beta$ transgenic tobacco infected with ToLCV

It has been reported that $\mathrm{CLCuMuB}$ was rescued from a dimeric $\beta$ transgenic tobacco plant ( $2 \beta$ tobacco) upon ToLCV infection (Saeed et al., 2005). CLCuMuB molecules should be present in all cell types of both vascular and non-vascular tissues of $2 \beta$ transgenic tobacco. To investigate the localization pattern of ToLCV and rescued CLCuMuB molecules, in situ hybridization was performed on sections of $2 \beta$ transgenic tobacco infected with ToLCV. Hybridization signals were found only in the vascular cells of infected $2 \beta$ transgenic tobacco plants using a complementary-sense RNA probe either specific to CLCuMuB (Fig. 4B) or to ToLCV (Fig. 4C). Following hybridization with the $\mathrm{CLCuMuB}$-specific probe designed to detect $\beta C 1$ specific RNA transcripts (virion-sense RNA probe from the $\beta C 1 \mathrm{ORF}$ ), chromogenic signals were not detected in the section from the non-inoculated plant, suggesting that transcripts, if present, are probably below detection level (Fig. 4A).

Expression of $\beta \mathrm{C} 1$ from $\mathrm{CLCuMuB}$ in transgenic plants induces abnormal cell division.

Transgenic plants containing a dimer of CLCuMuB, called $2 \beta$, showed abnormal phenotypes (Saeed et al., 2005). When these abnormalities in $2 \beta$ transgenic plants were examined at the cellular level, large clusters of hyperplastic cells were frequently observed to be associated with the vascular tissue (Fig. 5). These abnormal cell structures were not found outside the vasculature. Such hyperplastic cells were also not observed in non-transgenic tobacco. plants

Tissue specificity of CLCuMuB $\beta C 1$ promoter in transgenic

The GUS expression pattern conferred by the $\beta 989$ in mature leaf tissue was determined in five different transgenic
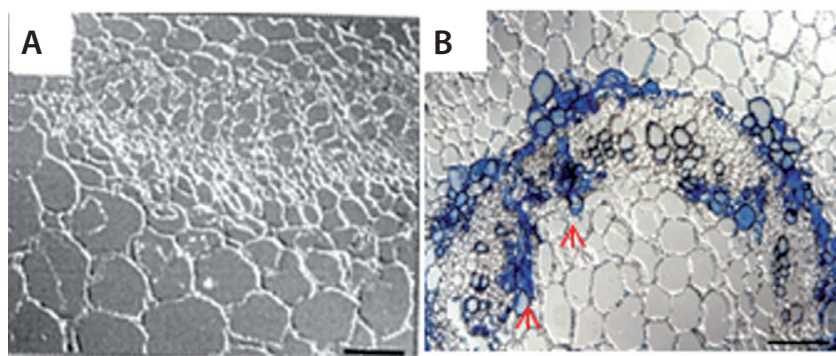

c
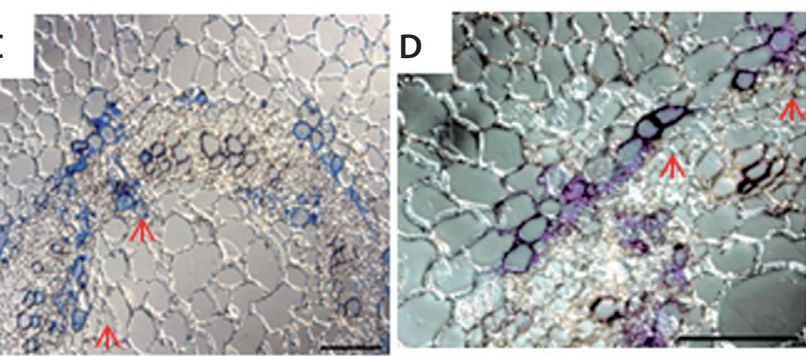

Fig. 3

In situ localization of CLCuMuB with the helper viruses, ToLCV, in infected plants

Transverse sections of N. benthamiana uninfected plant (A), infected with ToLCV alone (B) or together with CLCuMuB (C and D). Sections were hybridized with digoxigenin (DIG)-labelled complementary-sense ssRNA from the C4 ORF of ToLCV (B) and $\beta C 1$ ORF from CLCuMuB (C). Fluorescein-labelled ToLCV-specific probe and DIG-labelled CLCuMuB-specific probes were used in dual in situ hybridization that exhibits a distinct purple chromogenic output due to the masking of red ToLCV signals by the blue CLCuMuB signals (D). Red arrows represent the hybridization signals. Bars $=100 \mu \mathrm{m}$. 


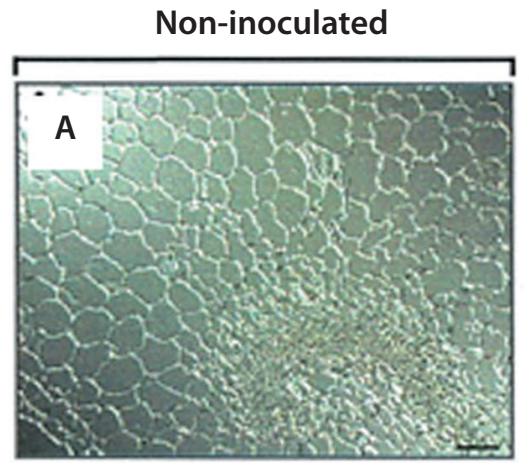

VS ssRNA probe from the $\beta C 1$ ORF

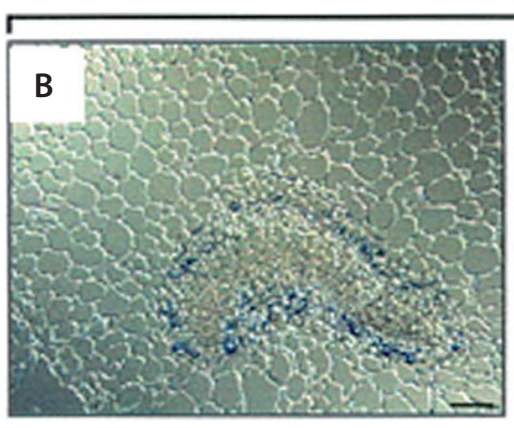

CS ssRNA probe from the $\beta C 1$ ORF
TLVC-inoculated

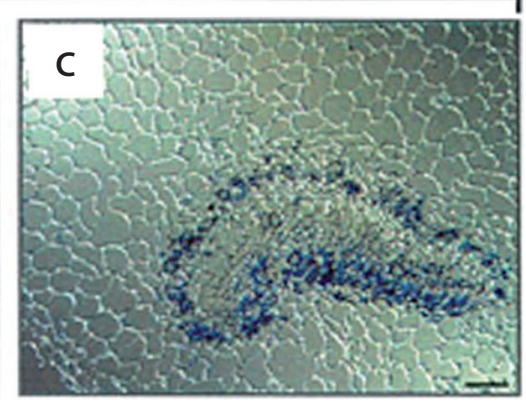

CS ssRNA probe from the C4 ORF of TLCV

Fig. 4

In situ localization of CLCuMuB in $2 \beta$ transgenic plants inoculated with ToLCV

Transverse sections of $2 \beta$ transgenic plants (A-C). Section shown in (A) was hybridized to detect $\beta C 1$ mRNA in non-inoculated plants. Sections (B) and (C) show the accumulation of $\mathrm{ClCuMuB}$ and ToLCV in the infected plants, respectively. Viral infections and type of probe used are indicated. VS $=$ virion sense, $\mathrm{CS}=$ complementary sense. Bars $=100 \mu \mathrm{m}$.
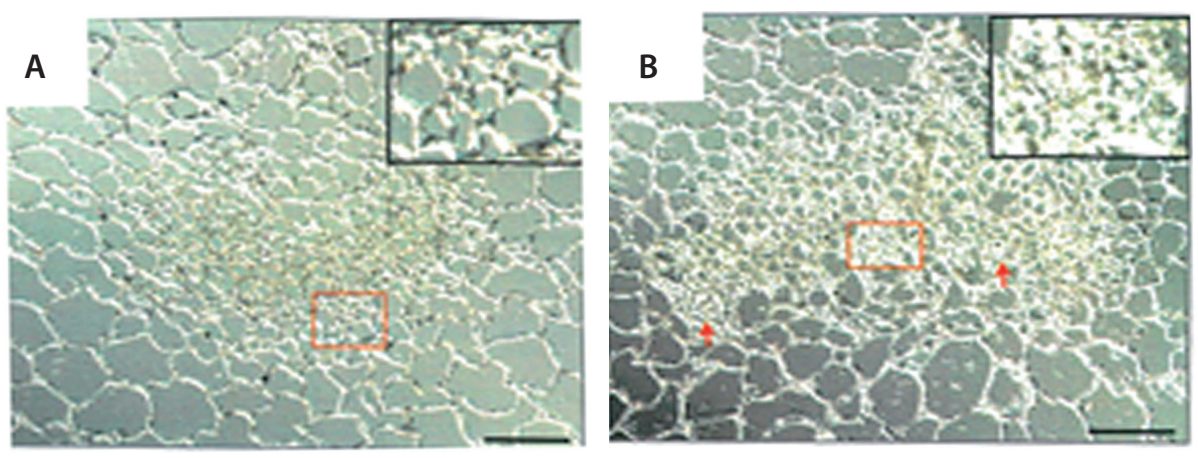

Fig. 5

Hyperplastic cells in $2 \beta$ transgenic plants

Transverse sections of $2 \beta$ transgenic plants showing groups of hyperplastic cells indicated by red arrows (B). A section from a non-transgenic plant is shown in the left panel (A). A higher magnitude of tissues is provided on the right corner of each panel. Bars $=100 \mu \mathrm{m}$.

tobacco lines. All lines showed GUS staining associated with the vascular tissue. Line $\beta 989-3$ was used for detailed histochemical analysis. In leaf cross sections, GUS expression was strongest in vascular tissue, mainly in the phloem tissues (Fig. 6a). No GUS activity was detected in mesophyll and epidermal cells. These expression patterns were compared with $35 \mathrm{~S}$ promoter from CaMV, which is active in all types of plant tissues (Fig. 6a).

\section{$\beta C 1$ promoter activity in transgenic tobacco}

To analyse the promoter activity of CLCuMuB in a stable system, transgenic tobacco plants containing a full-length $\beta C 1$ promoter-GUS (called $\beta 989$ ) cassette were generated. The expression of GUS was tested by Northern blot. A significantly lower level of GUS expression was observed in $\beta 989$ transgenic lines compared to the pBI121 plants that drive GUS expression under a strong and ubiquitous promoter, 2× 35S from CaMV (Fig. 6b).

We also used another approach to investigate the activity of $\beta C 1$ promoter in $\beta 989$ transgenic lines. Quantitative GUS fluorometric assays also showed a low level of GUS production in the tested plants compared to the pBI121 plants (Fig. 6c). This may indicate a weak promoter activity for $\beta \mathrm{C} 1$ promoter or activity of this promoter in a limited part of the plant tissue.

\section{Discussion}

Most characterized betasatellites are associated with monopartite begomoviruses (Zhou, 2013), except for a novel 
(a)
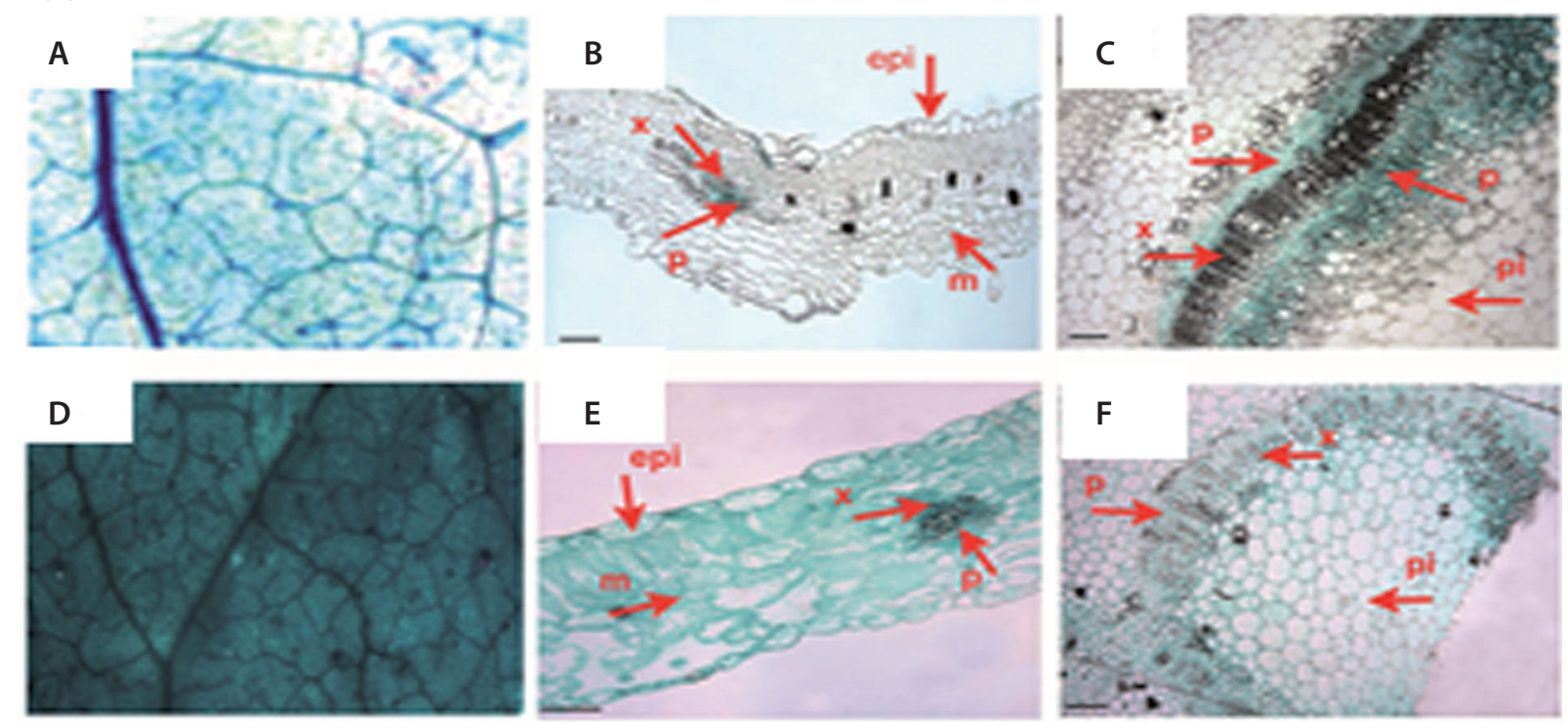

(b)

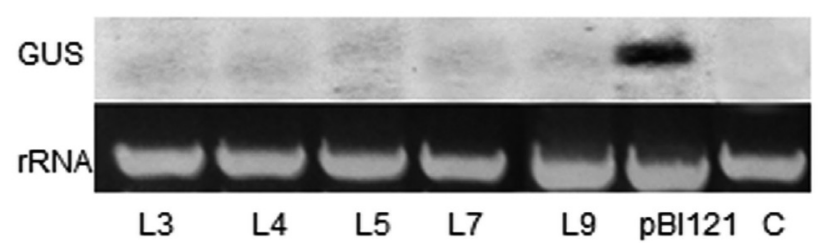

(c)

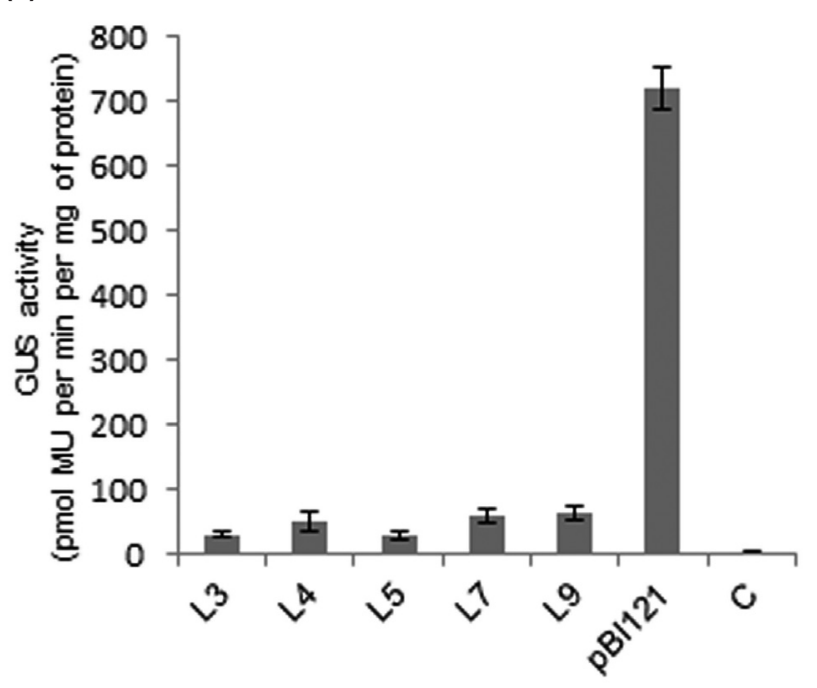

Fig. 6

Expression pattern and activity of $\beta \mathrm{C} 1$ promoter compared with CaMV $35 \mathrm{~S}$ promoter in transgenic tobacco plants (a) Histochemical localization of GUS in transgenic tobacco plants containing full length CLCuMuB promoter-GUS ( $\beta 989$ ) in the leaf slice (A) and transverse sections through the transgenic tobacco leaf (B) and stem (C) compared with the constitutive expression of GUS under CaMV 35S promoter in the leaf disc (D) and transverse section of leaf (E) and stem (F). p, phloem; x, xylem; epi, epiderm; pi, pith; m, mesophyll. Scale bars $=100 \mu \mathrm{m}$. (b) Northern blotting assay shows expression of GUS in five individual lines of transgenic $\beta 989$ plants, pBI121 and wild-type plants. The lower panel shows the level of total RNA loaded for each sample. (c) Quantitative GUS fluorometric results shows the GUS activity in five individual lines of $\beta 989$ and pBI121 plants. Wild type plants were used as control, C. Six replicates were used for each line; means \pm SD are shown.

class of DNA satellites, which have been recently found to be associated with a bipartite begomovirus in malvaceous plants (Fiallo-Olivé et al., 2012) and a betasatellite, which has been reported to be associated with wheat dwarf Indian virus, a mastrevirus (Kumar et al., 2014). Betasatellites in monopartite begomoviruses are analogous to DNA B in bipartite begomoviruses (Briddon and Stanley, 2006). The $\beta \mathrm{C} 1$ protein of $\mathrm{CLCuMuB}$ was shown to bind to long single stranded and double stranded DNA (Saeed et al., 2015). It has been suggested that this protein mediates virus movement in plants (Cui et al., 2005; Saeed et al., 2007). Substitution of DNA B with a betasatellite also supported systemic infection 
of DNA A in tomato leaf curl New Delhi virus, a bipartite begomovirus (Saeed et al., 2007). It has been suggested that DNA B of bipartite begomoviruses can be involved in mesophyll invasion (Rojas et al., 2005) and co-infection with a mesophyll-invasive bipartite begomovirus, TGMV, was shown to release bean golden mosaic virus from phloem to mesophyll tissues in infected plants (Morra and Petty, 2000). Therefore, we tested the possibility that betasatellite may affect tissue specificity of helper viruses, which was shown for DNA B components of bipartite begomoviruses. However, two lines of evidence in this study, including in situ hybridization and localization of ToLCV in the vascular tissue of $2 \beta$ transgenic plants infected with this virus, did not support this assumption. Indeed, both cognate, CLCuMuV (data not shown), and non-cognate, ToLCV, helper viruses remained in the phloem tissue in the presence of CLCuMuB. Localization of CLCuMuB and the helper virus in phloem cells is reported for the first time in this study.

The evolutionary origin of betasatellites is not known. It has been assumed that betasatellites may have evolved from a pre-existing component by association with a monopartite begomovirus (Mansoor et al., 2003). A recombination between DNA A and betasatellite of ageratum yellow vein betasatellite (AYVB) has been reported to produce a viable betasatellite recombinant (Saunders et al., 2001). Analysis of the sequences of CLCuMuB also showed extensive sequence variation, most likely resulting from recombination (Akhtar et al., 2014). A prerequisite for such a recombination is the replication of different viruses within the same cell. The result of this study suggests that tissue specificity may provide the opportunity for such an evolutionary process.

The $\beta C 1$ gene of CLCuMuB is a suppressor of host gene silencing (Eini et al., 2012). Ectopic expression of a silencing suppressor, $p 23$ from citrus tristeza virus, was found to modify tissue tropism of the virus from the phloem tissue to the mesophyll tissue (Fagoaga et al., 2011), whereas expression of $\beta C 1$ in infected plants was unable to release the phloem-limited helper viruses to non-phloem tissues. This indicated the functional variation between $\mathrm{p} 23$ and $\beta \mathrm{C} 1$ from two distinct groups of plant viruses. Therefore, other genetic elements from CLCuMuB and helper viruses may determine tissue tropism in infected plants. Indeed, compatibility between two movement proteins, BL1 and BR1, was found to be required for mesophyll invasion in TGMV, a bipartite begomovirus, (Morra and Petty, 2000). This suggests that $\beta C 1$ alone may not support mesophyll invasion and needs another compatible viral protein.

The properties of a viral promoter can determine the tissue specificity of the virus (Yin et al., 1997a). For example, the noncoding region upstream of the BR1 ORF of TGMV together with AL2/3, BL1 and BR1 has been shown to determine tissue tropism (i.e. mesophyll cells) of the virus (Morra and Petty, 2000). A phloem-specific promoter has been reported from geminiviruses, including wheat dwarf virus (Dinant et al., 2004), maize streak virus (Mazithulela et al., 2000), the C2/C3 promoter of a monopartite begomovirus ToLCV (Dry et al., 2000), and also from coconut foliar decay virus (Rohde et al., 1995) and rice tungro bacilliform virus (Yin et al., 1997b). In histochemical GUS staining experiments, expression of GUS under the full length of CLCuMuB $\beta \mathrm{C} 1$ promoter showed phloem-specific activity in transgenic $\beta 989$ tobacco lines. Similarly, phloem-specific promoter activity for tomato yellow leaf curl China betasatellite has been reported (Guan and Zhou, 2006). Therefore, phloem-limited helper viruses, ToLCV and CLCuMuV (data not shown), are not the sole determinant for limiting the CLCuMuB into the phloem cells.

A low level of GUS expression under the $\beta C 1$ promoter of CLCuMuB in transgenic plants is consistent with the earlier observation that accumulation of $\beta C 1 \mathrm{mRNA}$ is low in $2 \beta$ transgenic tobacco (Saeed et al., 2005). It needs to be noted that phloem-specific activity of $\beta C 1$ promoter limits the expression of the GUS gene in $\beta 989$ plants and $\beta C 1$ in $2 \beta$ plants to a small part of the leaf tissue. Therefore, comparing a $\beta C 1$ promoter with $2 \times 35$ S promoter, which is an ubiquitous promoter, may not reflect the intrinsic strength of the $\beta C 1$ promoter.

Further support for vascular localization of CLCuMuB and its tissue-specific promoter avidity come from specific cell proliferation in vascular bundles in $2 \beta$ transgenic plants (Fig. 4), which also resembles cell proliferation in vascular bundles of transgenic plants expressing another $\beta C 1$ gene from Ageratum yellow vein betasatellite (AYVB) (Saunders et al., 2004). Indeed, both CLCuMuB (Saeed et al., 2005; Eini et al., 2009b) and AYVB (Saunders et al., 2004) produced a specific vein-greening and vein-swelling phenotype in infected tobacco plants that supports their tissue specificity.

Two lines of evidence, including localization of the helper virus and phloem-specific activity of CLCuMuB promoter, lead to the conclusion that CLCuMuB is localized in the phloem tissue. Unlike DNA B in bipartite begomoviruses and some viral suppressor proteins, CLCuMuB did not affect the tissue tropism of the monopartite helper begomovirus. A more comprehensive study is required to understand the association of this phloem-specific begomovirus-betasatellite with leaf curling disease complex to design control strategies for this increasing threat to global agriculture.

Acknowledgements. We thank Dr. Rob W. Briddon for the gift of the CLCuMuB clone and Dr. Muhammad Saeed for his scientific support. O. Eini was supported by MSRT, Iran and M. S. Rasheed was supported by an ACIAR/John Allwright Fellowship.

\section{References}

Akhtar S, Tahir MN, Baloch GR, Javaid S, Khan AQ, Amin I, Briddon RW, Mansoor S (2014): Regional changes in the 
sequence of cotton leaf curl Multan betasatellite. Viruses 6, 2186-2203. https://doi.org/10.3390/v6052186

Bian X, Rasheed MS, Seemanpillai MJ, Rezaian MA (2006): Analysis of silencing escape of Tomato leaf curl virus: an evaluation of the role of DNA methylation. Mol. Plant Microbe In. 19, 614-624. https://doi.org/10.1094/MPMI-19-0614

Briddon RW, Mansoor S, Bedford ID, Pinner MS, Markham PG (2000): Clones of cotton leaf curl geminivirus induce symptoms atypical of cotton leaf curl disease. Virus Genes 20, 19-26. https://doi.org/10.1023/A:1008151921937

Briddon RW, Mansoor S, Bedford ID, Pinner MS, Saunders K, Stanley J, Zafar Y, Malik KA, Markham PG (2001): Identification of DNA components required for induction of cotton leaf curl disease. Virology 285, 234-243. https:// doi.org/10.1006/viro.2001.0949

Briddon RW, Stanley J (2006): Sub-viral agents associated with plantinfecting single-stranded DNA viruses. Virology 344 , 198-210. https://doi.org/10.1016/j.virol.2005.09.042

Cui X, Li G, Wang D, Hu D, Zhou X (2005): A begomovirus DNA $\beta$ encoded protein binds DNA, functions as a suppressor of RNA silencing, and targets the cell nucleus. J. Virol. 79, 10764-10775. https://doi.org/10.1128/JVI.79.16.1076410775.2005

Cui XF, Xie Y, Zhou XP (2004): Molecular characterization of DNA molecules associated with tobacco leaf curl Yunnan virus. J. Phytopathol. 152, 647-650. https://doi. org/10.1111/j.1439-0434.2004.00911.x

Dinant S, Ripoll C, Pieper M, David C (2004): Phloem specific expression driven by wheat dwarf geminivirus $\mathrm{V}$-sense promoter in transgenic dicotyledonous species. Physiol. Plant. 121, 108116. https://doi.org/10.1111/j.0031-9317.2004.00296.x

Dry I, Krake L, Mullineaux P, Rezaian A (2000): Regulation of tomato leaf curl viral gene expression in host tissues. Mol. Plant Microbe In. 13, 529-537. https://doi.org/10.1094/ MPMI.2000.13.5.529

Dry IB, Rigden JE, Krake LR, Mullineaux PM, Rezaian MA (1993): Nucleotide sequence and genome organization of tomato leaf curl geminivirus. J. Gen. Virol. 74, 147-151. https:// doi.org/10.1099/0022-1317-74-1-147

Eini O, Behjatnia SAA, Dogra S, Dry IB, Randles JW, Rezaian MA (2009a): Identification of sequence elements regulating promoter activity and replication of a monopartite begomovirus-associated DNA beta satellite. J. Gen. Virol. 90, 253-260. https://doi.org/10.1099/vir.0.002980-0

Eini O, Dogra S, Selth LA, Dry IB, Randles JW, Rezaian MA (2009b): Interaction with a host ubiquitin-conjugating enzyme is required for the pathogenicity of a geminiviral DNA $\beta$ satellite. Mol. Plant Microbe In. 22, 737-746. https://doi. org/10.1094/MPMI-22-6-0737

Eini O, Dogra SC, Dry IB, Randles JW (2012): Silencing suppressor activity of a begomovirus DNA $\beta$ encoded protein and its effect on heterologous helper virus replication. Virus Rres. 167, 97-101. https://doi.org/10.1016/j. virusres.2012.03.012

Fagoaga C, Pensabene-Bellavia G, Moreno P, Navarro L, Flores R, PeÑA L (2011): Ectopic expression of the p23 silencing suppressor of Citrus tristeza virus differentially modifies viral accumulation and tropism in two transgenic woody hosts. Mol. Plant Pathol. 12, 898-910. https://doi. org/10.1111/j.1364-3703.2011.00722.x

Fiallo-Olivé E, Martínez-Zubiaur Y, Moriones E, Navas-Castillo J (2012): A novel class of DNA satellites associated with New World begomoviruses. Virology 426, 1-6. https:// doi.org/10.1016/j.virol.2012.01.024

Gopal P, Pravin Kumar P, Sinilal B, Jose J, Kasin Yadunandam A, Usha R (2007): Differential roles of C4 and $\beta C 1$ in mediating suppression of post-transcriptional gene silencing: Evidence for transactivation by the $\mathrm{C} 2$ of Bhendi yellow vein mosaic virus, a monopartite begomovirus. Virus Res. 123, 9-18. https://doi.org/10.1016/j. virusres.2006.07.014

Guan C, Zhou X (2006): Phloem specific promoter from a satellite associated with a DNA virus. Virus Res. 115, 150-157. https://doi.org/10.1016/j.virusres.2005.08.002

Horsch RB, Fry JE, Hoffmann NL, Eichholtz D, Rogers SG, Fraley RT (1985): A simple and general method for transferring genes into plants. Science 227, 1229-1231. https://doi. org/10.1126/science.227.4691.1229

Jefferson RA, Kavanagh TA, Bevan MW (1987): GUS fusions: $\mathrm{B}$-glucuronidase as a sensitive and versatile gene fusion marker in higher plants. EMBO J. 6, 3901 -3907.

Kheyr-Pour A, Bendahmane M, Matzeit V, Accotto GP, Crespi S, Gronenborn B (1991): Tomato yellow leaf curl virus from Sardinia is a whitefly-transmitted monopartite geminivirus. Nucleic Acids Res. 19, 6763-6769. https:// doi.org/10.1093/nar/19.24.6763

Kumar J, Kumar J, Singh SP, Tuli R (2014): Association of satellites with a mastrevirus in natural infection: Complexity of wheat dwarf India virus disease. J. Virol. 88, 7093-7104. https://doi.org/10.1128/JVI.02911-13

Levy A, Czosnek H (2003): The DNA-B of the non-phloem-limited bean dwarf mosaic virus (BDMV) is able to move the phloem-limited Abutilon mosaic virus (AbMV) out of the phloem, but DNA-B of AbMV is unable to confine BDMV to the phloem. Plant Mol. Biol. 53, 789-803. https://doi. org/10.1023/B:PLAN.0000023662.25756.43

Mansoor S, Briddon RW, Zafar Y, Stanley J (2003): Geminivirus disease complexes: an emerging threat. Trends Plant Sci. 8, 128-134. https://doi.org/10.1016/S1360-1385(03)00007-4

Mazithulela G, Sudhakar D, Heckel T, Mehlo L, Christou P, Davies JW, Boulton MI (2000): The maize streak virus coat protein transcription unit exhibits tissue-specific expression in transgenic rice. Plant Sci. 155, 21-29. https://doi. org/10.1016/S0168-9452(99)00256-3

McFadden GI (1989): In situ hybridisation in plants: From macroscopic to ultrastructural resolution. Cell Biol. Int. Rep. 13, 3-21. https://doi.org/10.1016/S0309-1651(89)80004-9

Morra MR, Petty ITD (2000): Tissue specificity of geminivirus infection is genetically determined. Plant Cell 12, 22592270. https://doi.org/10.1105/tpc.12.11.2259

Rohde W, Becker D, Randles JW (1995): The promoter of coconut foliar decay-associated circular single-stranded DNA directs phloem-specific reporter gene expression in transgenic tobacco. Plant Mol. Biol. 27, 623-628. https:// doi.org/10.1007/BF00019328 
Rojas MR, Hagen C, Lucas WJ, Gilbertson RL (2005): Exploiting chinks in the plant's armur: Evulution and emergence of geminiviruses. Annu. Rev. Phytopathol. 43, 361-394. https://doi.org/10.1146/annurev.phyto.43.040204.135939

Rojas MR, Jiang H, Salati R, Xoconostle-Cázares B, Sudarshana MR, Lucas WJ, Gilbertson RL (2001): Functional analysis of proteins involved in movement of the monopartite begomovirus, tomato yellow leaf curl virus. Virology 291, 110-125. https://doi.org/10.1006/viro.2001.1194

Saeed M, Behjatnia SAA, Shahid M, Yusuf Z, Shahida H, Rezaian MA (2005): A single complementary-sense transcript of a geminiviral DNA beta satellite is determinant of pathogenicity. Mol. Plant Microbe In. 18, 7-14. https:// doi.org/10.1094/MPMI-18-0007

Saeed M, Briddon RW, Dalakouras A, Krczal G, Wassenegger M (2015): Functional Analysis of Cotton Leaf Curl Kokhran Virus/Cotton Leaf Curl Multan Betasatellite RNA Silencing Suppressors. Biology 4, 697-714. https://doi. org/10.3390/biology 4040697

Saeed M, Zafar Y, Randles JW, Rezaian MA (2007): A monopartite begomovirus-associated DNA beta satellite substitutes for the DNA B of a bipartite begomovirus to permit systemic infection. J. Gen. Virol. 88, 2881-2889. https:// doi.org/10.1099/vir.0.83049-0

Sambrook L, Russell DW (2001): Molecular Cloning: A Laboratory Manual. Cold spring Harbor Laboratory Press, New York, pp. 181-197.

Saunders K, Bedford ID, Stanley J (2001): Pathogenicity of a natural recombinant associated with ageratum yellow vein disease: implications for geminivirus evolution and disease aetiology. Virology 282, 38-47. https://doi.org/10.1006/ viro.2000.0832

Saunders K, Norman A, Gucciardo S, Stanley J (2004): The DNA beta satellite component associated with ageratum yellow vein disease encodes an essential pathogenicity protein ( BC1). Virology 324, 37-47. https://doi.org/10.1016/j. virol.2004.03.018
Selth LA, Dogra SC, Rasheed MS, Healy H, Randles JW, Rezaian MA (2005): A NAC domain protein interacts with tomato leaf curl virus replication accessory protein and enhances viral replication. Plant Cell 17, 311-325. https://doi. org $/ 10.1105 /$ tpc. 104.027235

Spurr AP (1969): A low viscosity epoxy resin embedding medium for electron microscopy. J. Ultrastruct. Res. 26, 31-34. https://doi.org/10.1016/S0022-5320(69)90033-1

Stanley J, Bisaro DM, Briddon RW, Brown JK, Fauquet CM, Harrison BD, Rybicki EP, Stenger DC (2005): Geminiviridae. In Fauquet CM et al. (Eds): Virus Taxonomy. VIIIth Report of the International Committee on Taxonomy of Viruses, Accademic Press, London, pp. 301-326.

Stonor J, Hart P, Gunther M, DeBarro P, Rezaian MA (2003): Tomato leaf curl geminivirus in Australia: occurrence, detection, sequence diversity and host range. Plant Pathol. 52, 379-388. https://doi.org/10.1046/j.1365-3059 2003.00854.x

Wege C, Saunders K, Stanley J, Jeske H (2001): Comparative analysis of tissue tropism of bipartite geminiviruses. J. Phytopathol. 149, 359-368. https://doi.org/10.1046/j.1439$\underline{0434.2001 .00640 . \mathrm{x}}$

Weigel K, Pohl JO, Wege C, Jeske H (2015): A population genetics perspective on geminivirus infection. J. Virol. 89, 11926-11934. https://doi.org/10.1128/JVI.01956-15

Yin Y, Zhu Q, Dai S, Lamb C, Beachy RN (1997a): RF2a, a bZIP transcriptional activator of the phloem-specific rice tungro bacilliform virus promoter, functions in vascular development. EMBO J. 16, 5247-5259. https://doi. org/10.1093/emboj/16.17.5247

Yin Y, Chen L, Beachy RN (1997b): Promoter elements required for phloem-specific gene expression from the RTBV promoter in rice. Plant J. 12, 1179-1188. https://doi. org/10.1046/j.1365-313X.1997.12051179.x

Zhou X (2013): Advances in understanding begomovirus satellites. Annu. Rev. Phytopathol. 51, 357-381. https://doi. org/10.1146/annurev-phyto-082712-102234 